\title{
Ensino de língua portuguesa e memes: outros textos, outras leituras
}

\section{Teaching the Portuguese language and internet memes: expanding discursive and multimodal actions in educational blogs}

\author{
Isnalda Berger de F. Alves Filha* \\ Universidade Estadual de Feira de Santana \\ Feira de Santana, Bahia, Brasil \\ Úrsula Cunha Anecleto** \\ Universidade do Estado da Babia \\ Coité, Bahia, Brasil
}

\begin{abstract}
Resumo: Neste artigo; discutimos sobre a importância do trabalho com textos multimodais e multissemióticos, a exemplo dos memes, no ensino de Língua Portuguesa, na educação básica. Tem por objetivo discutir as possibilidades de ações discursivas geradas a partir da leitura desses memes que circulam em novas esferas públicas, a exemplo do gênero discursivo blog. Como referencial teórico, ancora-se nos estudos sobre racionalidade comunicativa e a ação discursiva (HABERMAS, 2012); esfera pública (HABERMAS, 1984; 1997) e memes (RECUERO, 2009). Enfatizamos que a esfera pública é um espaço para debate, formação de opinião, a partir do melhor argumento e, nesse sentido, torna-se importante criar oportunidades na educação básica para os estudantes atuarem, de forma mais autônoma, sobre as mídias digitais, sustentando suas opiniões e desenvolvendo argumentos nesses espaços emergentes, possibilitando a ampliação de ações discursivas com vista a uma racionalidade comunicativa.
\end{abstract}

Palavras- chave: ensino de língua portuguesa; ações discursivas; memes.

Abstract: In this article we discuss the importance of working with multimodal and multisemiotic texts, like the memes of internet, in Portuguese language teaching, in basic education. It aims to discuss the possibilities of discursive actions generated from reading these memes that circulate in new public spheres, such as the discursive genre blog. As a theoretical reference, it is anchored in the studies on communicative rationality and discursive action (Habermas, 2012); public sphere (HABERMAS, 1984; 1997) and internet memes (RECUERO, 2009). We emphasize that the public sphere is a space for debate, opinion formation, based on the best argument, and regarding such meaning, it is important to create opportunities in basic education for students to act more autonomously on digital media, sustaining their opinions and developing their pleas in these emerging spaces, enabling the expansion of discursive actions that look forward to a communicative rationality.

Keyword: Portuguese language teaching; discursive actions; internet memes

* Aluna do mestrado em Estudos Linguísticos, da Universidade Estadual de Feira de Santana: nalfigueiredo2@hotmail.com.

** Doutora em Letras e docente no Mestrado Profissional em Educação e Diversidade (MPED/UNEB, no Mestrado em Estudos Linguísticos (MEL/UEFS) e no Departamento de Educação, da Universidade do Estado da Bahia (UNEB / campus XIV), Conceição do Coité Bahia - Brasil.Email: ursula.cunha@hotmail.com. 


\section{INTRODUÇÃO}

Sabemos que as tecnologias digitais (TD) conectadas à internet, a partir de suas potencialidades interativas, possibilitaram o surgimento de outras esferas públicas, a exemplo das redes sociais, blogs, aplicativos de mensagens, legitimando esses espaços enquanto rede de comunicação de conteúdos, informações, opiniões etc. (HABERMAS, 1997) entre os sujeitos. Dessa forma, contribuíram com a propagação de novos gêneros discursivos, a exemplo dos blogs, e de fenômenos linguístico-comunicativos, como os memes, que têm estreita relação com a rápida disseminação de informações nos espaços virtuais.

Nessa perspectiva, as TD assumem um papel de destaque para o surgimento e desenvolvimento de esferas públicas. Através delas, os sujeitos podem agir, comunicativamente, uns com os outros, problematizando e emitindo opiniões sobre diversos temas, mediatizados por uma gama de gêneros discursivos que fazem parte do processo textual multifacetado da atualidade.

Assim, afirmamos a importância de os estudantes da educação básica lerem e compreenderem textos que circulam nessas esferas públicas, caracterizados pela multimodalidade, hibridismo textual e multissemiose. E, para isso, é necessário rever práticas pedagógicas do professor em sala de aula, no sentido em que docentes levem em conta essa diversidade textual oriunda desses meios virtuais.

Este artigo apresenta um recorte de uma dissertação de mestrado, ainda em andamento, que pretende investigar como alunos de uma escola pública do Ensino Fundamental dão sentido à leitura de memes, postados em um blog educacional, e ampliam, assim, suas ações discursivas. Trata-se de estudo teórico-reflexivo sobre processos de interação ${ }^{1}$, com base na Teoria do Agir Comunicativo (HABERMAS, 1997; 2012; 2010), da multimodalidade (RIBEIRO, 2016) e de gênero discursivo (BAKHTIN, 1997).

Algumas razões justificam a escolha dos memes para desenvolver este trabalho. Acreditamos que o estudo dos textos multimodais nas aulas de Língua Portuguesa é bastante limitado, necessitando, assim, de práticas que explorem não somente a estrutura, mas considerem a sua funcionalidade comunicativa, as relações entre autor, leitor e sua relação com contextos sócio-históricos. Atualmente, os memes têm ganhado destaque nas mídias digitais e também fazem parte do cotidiano de professores e de estudantes. Nesse sentido, tornam-se um meio importante para oportunizar a reflexão sobre temas atuais, desenvolvendo o senso crítico dos alunos nessa fase de escolarização.

\footnotetext{
1 As interações, para Habermas (2010), acontecem a partir de duas formas de ação linguística: a comunicativa e a discursiva. As ações mediadas pelo discurso ocorrem quando as pretensões de validade de determinado tema são problematizadas, superando, assim, a própria ação comunicativa. Nesse sentido, as argumentações, que são a égide da ação discursiva, têm a finalidade de levar os sujeitos a entenderem-se mutuamente, com vistas a alcançarem um comum acordo sobre algo tematizado, ou seja, restabelecer a ação comunicativa: interação simbolicamente mediada; opera com a finalidade de gerar entendimento mútuo, de forma não coativa, através da superação de conflitos de ação.
} 
Nesse contexto, ao questionarmos como a leitura de memes contribui para a interação, chamadas por Habermas (2010) de ações discursivas, foi levantada a hipótese de que é importante que discentes da educação básica, a partir dos seus conhecimentos de mundo, adquiridos com o convívio social, leiam e compreendam textos multimodais, textos esses que se caracterizam pela rápida circulação nas mídias digitais e apresentam características e funcionalidades comunicativas peculiares, atentando para o fato de que as tecnologias digitais possibilitam maior participação do sujeito em esferas públicas.

\title{
2 TECNOLOGIAS DIGITAIS E O ENSINO DE LÍNGUA PORTUGUESA: OS MEMES EM QUESTÃO
}

O debate sobre a inserção das tecnologias digitais na sala de aula não é um fato recente para os estudos educacionais. Entretanto, ainda se torna necessário que relações mais estreitas entre esses meios e o ensino de Língua Portuguesa sejam empreendidas no âmbito escolar. Isso porque, com mudanças na comunicação, surgem, paralelamente, novas formas de expressão, de representação e de problematização da realidade. Atualmente, as tecnologias digitais ligadas à internet ampliaram espaços que dão aos sujeitos a oportunidade de expressarem opiniões e posicionarem-se criticamente, debatendo assuntos de interesse geral. Esses espaços caracterizam-se como esferas públicas, onde circulam gêneros discursivos com forte apelo visual, sonoro, de movimento etc.

De acordo com os PCN (BRASIL, 1997, p. 25-26),

\begin{abstract}
Toda educação verdadeiramente comprometida com o exercício da cidadania precisa criar condições para o desenvolvimento da capacidade de uso eficaz da linguagem que satisfaça necessidades pessoais - que podem estar relacionadas às ações efetivas do cotidiano, à transmissão e busca de informação, ao exercício da reflexão. De modo geral, os textos são produzidos, lidos e ouvidos em razão de finalidades desse tipo. Sem negar a importância dos que respondem a exigências práticas da vida diária, são os textos que favorecem a reflexão crítica e imaginativa, o exercício de formas de pensamento mais elaboradas e abstratas, os mais vitais para a plena participação numa sociedade letrada.
\end{abstract}

Dessa forma, o ensino de língua portuguesa deve ter como base o estudo dos textos que se materializam através de diversos gêneros discursivos, inclusive os que surgem nos espaços virtuais, favorecendo a interação dos estudantes e apropriação de diferentes linguagens. Os estudantes e professores, que também são usuários de aplicativos de mensagens, de redes sociais, de diversos ambientes virtuais, interagem constantemente nessas novas esferas públicas. Nesse contexto, o trabalho com memes, enquanto fenômeno linguístico-comunicativo, torna-se imperativo para docentes de língua portuguesa na educação básica.

É muito comum os memes serem tratados com superficialidade com o intuito apenas de provocar o riso; porém, como todo texto, não são ingênuos. Geralmente, abordam temas do cotidiano e com bastante evidência nas mídias digitais. Sendo assim, 
acreditamos ser uma oportunidade de estimular a leitura crítica dos estudantes, para que compreendam que a internet pode ser um espaço de troca de experiências, de formação de opinião e desenvolvimento do senso crítico. Para Antunes (2003, p. 81), "[...] a leitura se torna plena quando o leitor chega à interpretação dos aspectos ideológicos do texto, das concepções que, às vezes sutilmente, estão embutidos nas entrelinhas.".

Por tudo que foi exposto, reforçamos o importante papel da escola ao criar oportunidades para que os estudantes interajam de forma autônoma nas mídias digitais, levantando questões sobre responsabilidade e comprometimento em relação ao que é comentado e postado nesses espaços, sustentando suas opiniões e analisando a confiabilidade das informações que circulam de forma tão imediata. E um dos caminhos para desenvolver essas ações é estudando os textos que circulam nesses espaços emergentes.

\subsection{Interação em esferas públicas virtuais, gêneros discursivos e os memes}

Com o surgimento de outros espaços comunicacionais e de novas textualidades, problematiza-se a atuação dos sujeitos nessas novas esferas públicas, numa sociedade conectada em rede, com rápida circulação de informações.

Anecleto (2015, p. 24) ressalta que

A sociedade em rede, ao oportunizar que diversos sujeitos possam conectar-se através das redes de computadores, amplia a participação social em esferas públicas, de forma individual ou coletiva. Essas esferas são espaços emergentes, nos quais interesses gerais são expostos, controvertidos, debatidos, criticados para, então, dar lugar a um julgamento, síntese ou consenso.

Assim, a esfera pública, na Teoria do Agir Comunicativo (TAC), representa

[...] um lugar de formação de opinião, onde diversos assuntos podem ser tematizados, criticados, justificados etc. No entanto, o sujeito, para participar de uma esfera pública, deve ter a capacidade de argumentação e de crítica. [...] Assim, a esfera pública é o ambiente de formação e expressão da opinião pública, por meio linguísticos (ANECLETO, 2015, p. 25).

Por ter um caráter emergente, as esferas públicas não são espaços fechados, fortemente delimitados, como se fossem instituições e organizações com normas ou regras estabelecidas para participação. Elas estão inseridas nos meios sociais e são formadas por sujeitos atuantes, refletindo as mudanças e transformações da sociedade. Nas esferas públicas, os sujeitos têm a oportunidade de construir seus argumentos, formando opiniões, estabelecendo relações sociais através da linguagem (HABERMAS, 1997). 
A linguagem, então, “[...] constitui-se como elemento essencial para a interação social a partir de ações comunicativas, e tem como mecanismo a integração entre as pessoas" (ANECLETO, 2015. p. 26). Nesse ínterim, as tecnologias digitais possibilitaram o desenvolvimento de esferas públicas, como as redes sociais e outros ambientes virtuais, e a propagação de novos gêneros discursivos, a exemplo do Blog, "[...] ampliando os espaços da ação discursiva no cotidiano das pessoas e legitimando essas formas de interação mais amplas, públicas e linguisticamente híbridas" (ANECLETO, 2015, p. 24).

Em se tratando de interatividade, Lévy (1998, p. 44) argumenta que

O ciberespaço [...] permite, ao mesmo tempo, a reciprocidade na comunicação e a partilha de um contexto. Trata-se de comunicação conforme um dispositivo "todos para todos". Numa conferência eletrônica, por exemplo, uma pessoa envia uma mensagem a dezenas ou centenas de outras. Entre estas, algumas respondem. Depois, outras respondem à resposta, etc. Como todos as mensagens são registradas, sedimenta-se assim progressivamente uma memória, um contexto do grupo de discussão. Cabe salientar que essa memória, esse contexto comum, em vez de vir de um centro emissor Todo-Poderoso, emerge da interação entre os participantes.

Dessa forma, o espaço virtual possibilita a troca intensa de informações entre vários indivíduos interconectados que têm liberdade para publicar, atingindo um público ilimitado. O processo interativo no ciberespaço permite que o usuário acesse informações e também possibilita a intervenção, sendo possível publicar e modificar conteúdos. Assim, problematiza-se como os sujeitos atuam nas esferas públicas digitais ao deparar-se com situações de interação em que existem confrontos de ideias e opiniões dos sujeitos que lá estão inseridos.

A partir dessa concepção, evidenciam-se dois modos de interação na visão habermasiana: a ação comunicativa e a ação discursiva. " $\mathrm{Na}$ ação comunicativa, os sujeitos trocam informações sem, contudo, problematizar os enunciados proferidos pelo interlocutor. Em relação à ação discursiva, existe a problematização de pretensões de validade expressas pelo locutor" (ANECLETO, 2015, 29-30). Nesse sentido, quando os sujeitos interagem entre si, provocados pelos memes, por exemplo, centram-se em ações discursivas, a partir da problematização de temas, opiniões, argumentos etc. Entretanto, a partir dessas interações, a ação comunicativa pode ser estabelecida: momento em que os interlocutores, linguisticamente, chegam a um entendimento mútuo.

Nesse processo, os sujeitos podem interagir com e através dos memes, tendo como base os tipos de discurso apresentados por Habermas (2012): teórico, prático e explicativo. $\mathrm{O}$ discurso teórico tem como objetivo validar ou refutar a verdade de um argumento. Já o discurso prático corresponde a uma forma de argumentação em que a pretensão de validade das normas é problematizada no interior de um processo argumentativo, de forma dialógica e democrática. Quanto ao discurso explicativo, tem-se a necessidade de tornar claro uma argumentação incompreendida por algum integrante durante a ação discursiva. 
Os memes caracterizam-se pela multimodalidade e exigem novas formas de leitura. Equivocadamente, podem ser tomados como materiais de conteúdo raso, superficial, apenas divertido e engraçado, sem nenhuma seriedade. Porém, são capazes de problematizar aspectos sociais, apresentando elementos da cultura, veiculados a diversas situações cotidianas. Sendo assim, geram ações discursivas, dando oportunidade aos sujeitos de expressarem opiniões e posicionamentos críticos, a partir de sua leitura.

Devido a todo esse potencial interativo, os memes têm alcançado destaque nas mídias, evidenciando a agilidade dos usuários da rede ao criarem memes de forma rápida e criativa. Por isso, é importante conhecer alguns conceitos que ajudam a compreender a difusão de informação através dos memes e os elementos que o compõem: propósito comunicativo, multimodalidade e multissemiose. Entende-se como propósito comunicativo os objetivos que se deseja alcançar com os enunciados emitidos pelos sujeitos, ao produzirem textos multimodais, que se caracterizam pelo uso de diversas linguagens, a exemplo de sons, gestos, cores, imagens, símbolos etc. e multissemióticos que correspondem ao sistema de signos ou símbolos usados para compor o texto.

Recuero (2009), em seu livro Redes sociais na internet, explica que o estudo de memes tem sido tomado como base para compreender a difusão das informações em espaços virtuais e cita algumas características dos memes propostas por Dawkins (1979) e Blackmore (1999), tais como longevidade, fecundidade e fidelidade. Recuero (2009) enfatiza que

A longevidade é a capacidade do meme de permanecer no tempo. A fecundidade é sua capacidade de gerar cópias. Por fim, a fidelidade é a capacidade de gerar cópias com maior semelhança ao meme original. Ressalte-se que a propagação dos memes é cíclica e nem sempre implica a reprodução fiel da ideia original. Ao contrário, as mudanças e transformações são frequentes e comparadas, em sua abordagem, às mutações genéticas: essenciais para a sobrevivência do meme. Assim, as diferenças através das quais as pessoas repetem as ideias são, por definição, parte do meme (RECUERO, 2009, p. 124).

Essas são apenas algumas características dos memes, mas que dão suporte para compreendê-los como textos multimodais, linguisticamente híbridos e multissemióticos. Os sujeitos que interagem no espaço virtual, a exemplo dos estudantes da educação básica, precisam compreender e perceber os memes como novas formas de representação social, que apresentam elementos socioculturais, sendo provocados, por essas leituras, a expressarem opiniões e, assim, fomentarem debates sobre temas contemporâneos.

Entretanto, devido a todas essas características, os memes precisam ser apresentados aos estudantes dentro do espaço virtual, onde predomina a hipertextualidade ${ }^{2}$. Assim, eles podem ser encontrados em redes sociais, aplicativos de mensagens e em gêneros emergentes, a exemplo dos blogs.

${ }^{2}$ Entende-se a hipertextualidade como um novo processo de leitura e escrita caracterizado pela não linearidade. No ambiente virtual, o usuário da rede conduz a sua leitura/escrita de acordo com seus interesses a partir dos diversos links disponíveis nas páginas virtuais (MARCUSCHI, 2001). 


\title{
2.2 Gênero discursivo blog como espaço de circulação de memes
}

Para tratar do gênero discursivo blog, tomaremos como base as contribuições de Bakhtin (1997), que concebe gêneros discursivos como tipos relativamente estáveis de enunciados, vinculados a situações típicas de interação verbal. Reforça-se, também, a natureza sócio-ideológica dos gêneros, considerando-os como formas de ação social (MILLER, 2012).

Devido às necessidades comunicativas, não é possível delimitar a quantidade de gêneros que existem, pois sempre surgem e se renovam, de acordo com as mudanças sociais. Dessa forma,

\begin{abstract}
A diversidade desses gêneros deve-se ao fato de eles variarem conforme as circunstâncias, a posição social e o relacionamento pessoal dos parceiros: há o estilo elevado, estritamente oficial, diferente, como há o estilo familiar que comporta vários graus de familiaridade e de intimidade (distinguindo-se esta da familiaridade). Trata-se de gêneros que implicam também um tom determinado, ou seja, comportam em sua estrutura uma dada entonação expressiva. Estes gêneros, em particular os gêneros elevados, oficiais, são muito estáveis e muito prescritivos (normativos) (BAKHTIN, 1997, p. 302).
\end{abstract}

Os gêneros apresentam características distintas, que dependem da funcionalidade comunicativa. "O gênero une estabilidade e instabilidade, permanência e mudança. De um lado, reconhecem-se propriedades comuns em conjuntos de texto; de outro essas propriedades alteram-se continuamente" (FIORIN, 2016, p. 76). Ocorre que novos

[...] modos de ver e de conceptualizar a realidade implicam o aparecimento de novos gêneros e alteração dos já existentes. Ao mesmo tempo, novos gêneros ocasionam novas maneiras de ver a realidade. A aprendizagem dos modos sociais de fazer leva, concomitantemente, ao aprendizado dos modos sociais de dizer, os gêneros (FIORIN, 2016, p. 76-77).

O gênero discursivo blog, então, disseminou-se a partir do aparecimento das tecnologias digitais, proporcionando novas formas de comunicação, baseada na autoexpressão dos sujeitos, que culminaram em novas relações com a comunidade virtual. Enquanto gênero, Miller e Shepherd (2012) tratam das características do blog, a partir dos aspectos semióticos, o conteúdo semântico, traços sintáticos ou formais e seu valor pragmático como ação social. Além disso, citam gêneros que consideram como antecessores do blog, a exemplo do diário, serviço de clipagem, o impresso avulso, livro de citações e diário de bordo.

Os blogs são páginas pessoais que podem ser atualizadas a qualquer momento, disponibilizando links para sites e outros blogs. As primeiras versões caracterizavam-se como diários pessoais e, com o passar do tempo, foram ganhando novas características 
(MILLER, 2012). Atualmente existem, por exemplo, blogs políticos, educacionais e jornalísticos que atendem a um público diversificado.

Qualquer pessoa pode criar um blog e administrar a página virtual. Blogar caracteriza-se como uma ação social na esfera pública. Nesses espaços, os sujeitos tem a oportunidade de expressar-se sobre vários assuntos, postar comentários, caracterizandose como um ambiente de liberdade comunicativa.

Isso reforça ainda mais a concepção de blog como gênero discursivo, pois, além de suas características estruturais, a exemplo da multimodalidade e multissemiose, apresenta funcionalidade comunicativa baseada em postagens para diversos fins, proporcionando a interação entre indivíduos com interesses comuns. Esse gênero, por potencializar a interação entre os indivíduos, apresenta outras formas de leitura, a exemplo dos memes que, enquanto fenômenos que contribuem para a disseminação de informações, circulam nas esferas públicas a partir das tecnologias digitais.

Ilustrando como esses fenômenos linguístico-comunicativos, ou seja, os memes são importantes textos na formação leitora de estudantes da educação básica, apresentamos, a seguir, alguns exemplos que circularam em blogs da internet.

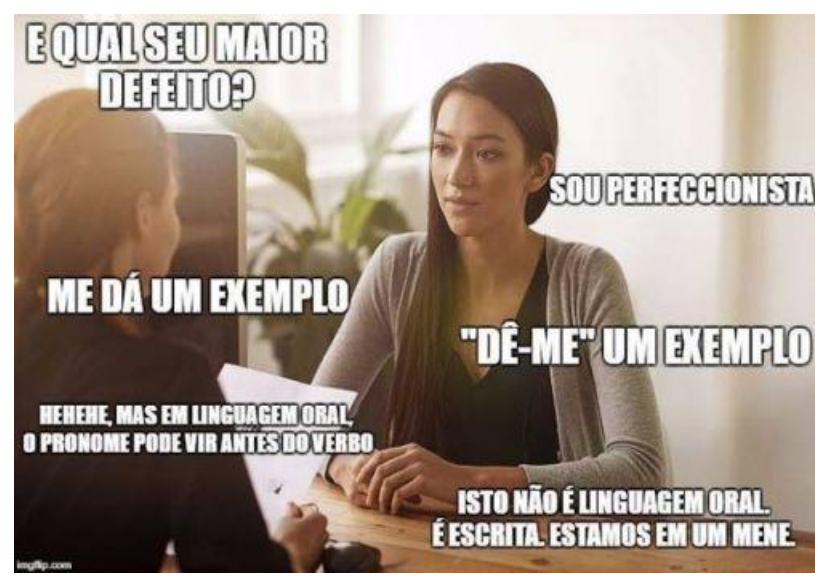

Figura 01: Meme

Fonte: http:/ / sitedosmenes.tumblr.com/post . Acesso em: 26 agosto 2017.

A Figura 1 apresenta, como temática principal, o uso da linguagem nos memes. Nota-se um caráter metalinguístico ao problematizar se esse tipo de meme se caracteriza pelo uso da linguagem escrita ou oral. A construção dos sentidos do texto se dá através da multimodalidade, com a combinação da linguagem verbal, representada pelo dialógico dos personagens, e a linguagem não verbal, com o uso da imagem estática, comum nesse tipo de meme.

Em relação aos elementos multissemióticos, ao analisar a cena, o leitor poderá identificar duas pessoas interagindo em um ambiente profissional e que, provavelmente, está sendo analisado um currículo e uma entrevista está sendo feita. Por veicular no blog Site dos Memes, permite aos sujeitos leitores (alunos da educação básica, por exemplo) 
apresentar subjetividade opinativa, propagação de ideias e a formação do sujeito autor sobre a tematização. Para isso, esses sujeitos apresentam, nessa esfera pública, a verdade da argumentação (discurso teórico) e a pretensão à norma (discurso prático).

No discurso teórico, por exemplo, problematiza-se sobre uso da linguagem e contexto comunicativo. É comum os estudantes da educação básica questionarem a verdade do proferimento apresentado no meme: utiliza-se, sempre, na forma escrita a forma enclítica do pronome oblíquo. Quanto ao discurso prático, leva-se em conta o questionamento à norma (como foi estabelecida essa norma de escrita? Quais sujeitos fizeram parte da elaboração dessa norma? etc.). O discurso explicativo, relativo à compreensão, seria utilizado caso se tornasse necessário deixar mais claro algum argumento no momento da interação.

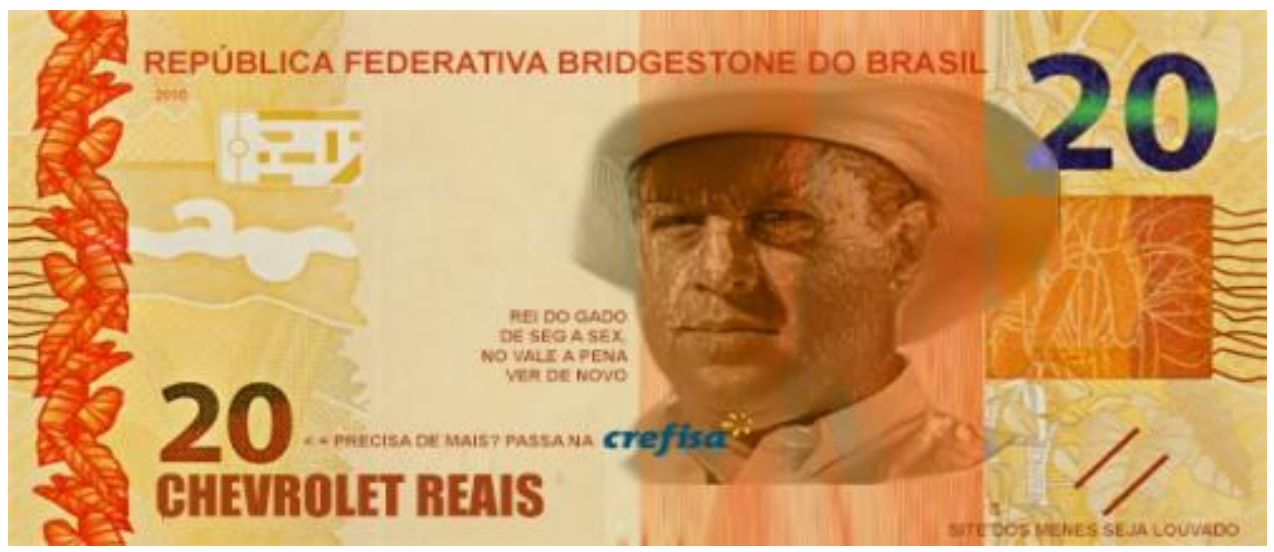

Figura 02: Meme

Fonte: sitedosmenes.tumblr.com/post . Acesso em: 26 agosto 2017.

A figura 2, veiculado no mesmo espaço do exemplo anterior, faz referência à recente notícia de privatização da Casa da Moeda do Brasil. De forma descontraída, o meme tem o propósito comunicativo de ironizar as ações do governo que passa o controle de instituições públicas para o setor privado. Em uma cédula de vinte reais, o criador do meme inclui o nome de várias empresas privadas de grande referência no setor econômico, simbolizando a venda da Casa da Moeda.

Em relação à multimodalidade, também se verifica a combinação de imagens e texto escrito. Esse aspecto pode ser notado através da identificação de nomes das empresas citadas no meme, além do uso da imagem de um personagem famoso em novelas globais (O Rei do Gado). Mais uma estratégica para a construção do humor do meme.

Esses dois exemplos de memes simbolizam algumas das funcionalidades comunicativas desse fenômeno que, veiculados em espaços virtuais, a exemplo dos blogs, permitem que o leitor exprima opiniões e promova debates sobre temas diversos.

\section{ALGUMAS CONSIDERAÇÕES}


Com este artigo, buscamos esclarecer a necessidade de compreender o surgimento de novas esferas públicas digitais e a propagação de fenômenos linguístico-comunicativos, que exigem dos sujeitos novos modos de ler no ciberespaço. Nesse contexto, evidenciamos como sujeitos promovem a construção de sentidos desses fenômenos, como os memes, ampliando suas ações discursivas, contribuindo, assim, para formação de opinião, debate, propagação de ideias e problematização da realidade.

Por suas características textuais e linguísticas, os memes são textos significativos que devem ser trabalhados nas aulas de Língua Portuguesa na educação básica, como forma de ampliar ações discursivas dos estudantes. Além disso, por se tratar de fenômenos que se propagam no mundo virtual, o gênero emergente blog representa um espaço ideal para que os sujeitos dialoguem com esses artefatos linguísticos e, também, exprimam seus argumentos, a partir da ação discursiva e/ou ação comunicativa.

\section{REFERÊNCIAS}

ANECLETO, Úrsula Cunha. Ação linguístico-comunicativa e práticas discursivas em esferas públicas na sociedade em rede. Revista A Cor das Letras, v. 16, p. 23-39, 2015.

ANTUNES, Irandé. Aulas de português: encontro e interação. São Paulo: Parábola Editorial, 2003.

BAKHTIN, M. Os gêneros do discurso. In: . Estética da criação verbal. Martins Fontes: São Paulo: 1997. p. 277-326.

BRASIL. Ministério da Educação. Secretaria de Educação Fundamental. Parâmetros Curriculares Nacionais: Lingua Portuguesa. V. 3. Brasília: MEC, 1997.

CRESWELL, John W. Projeto de Pesquisa: método qualitativo, quantitativo e misto. Tradução Magda Lopes. 3 ed. Porto Alegre: Artmed, 2010.

FERRO, Ana Paula R. A netnografia como metodologia de pesquisa: um recurso possível. Educação, Gestão e Sociedade: revista da Faculdade Eça de Queirós, ISSN 21799636, Ano 5, número 19, agosto de 2015.

FIORIN, José Luiz. Da necessidade da distinção entre texto e discurso. In. BRAIT, Beth; SILVA, Maria Cecília Souza e. Texto ou discurso? São Paulo: Contexto, 2012.

FIORIN, José Luiz. Introdução ao pensamento de Bakbtin. 2 ed. São Paulo: Contexto, 2016. p. 21-83.

HABERMAS, Jürgen. Direito e democracia: entre facticidade e validade. Vol. II. Rio de Janeiro: Tempo Brasileiro, 1997, p. 91-98. 
HABERMAS, Jürgen. Pensamento pós-metafísico: estudos filosóficos. Tradução Nachmetaphysisches Denken, Philosophische Ayfsätze. Rio de Janeiro: Tempo Brasileiro, 1990.

HABERMAS, Jürgen. Jürgen Habermas: obras escolhidas. Volume I. Tradução Lumir Nahodil. Lisboa: Edições 70, 2010.

HABERMAS, Jürgen. Teoria do agir comunicativo: racionalidade da ação e racionalização social. Vol 1. Tradução Paulo Astor Soethe. São Paulo: Editora WMF Martins Fontes, 2012.

LÉVY, Pierre. A Revolução contemporânea em matéria de comunicação. Revista Famecos. Porto Alegre, $n^{\circ}$ 9, p. 37-49, derembro 1998.

MARCUSCHI, L. A. O hipertexto como um novo espaço de escrita em sala de aula. Linguagem \& Ensino, Vol. 4, No. 1, 2001.

MILLER, Carolyn R.; SHEPHERD, Dawn.. Blogar como ação social: uma análise do gênero weblog. In. DIONÍSIO, Angela Paiva; HOFFNAGEL, Judith. (org.) Gênero textual, agência e tecnologia. São Paulo: Parábola Editorial, 2012, p. 59-86.

RECUERO, Raquel. Difusão de informação em redes sociais. In: Redes sociais na internet. Porto Alegre: Sulina, 2009, p. 116-134.

RIBEIRO, Ana Elisa. Textos multimodais: leitura e produção. São Paulo: Parábola Editorial, 2016. 